\title{
The Origin and Glyceride Distribution of Fatty Acids in Rat Adipose Tissue *
}

\author{
C. H. Hollenberg $\dagger$ \\ (From the McGill University Medical Clinic, Montreal General Hospital, Montreal, \\ Quebec, Canada)
}

Although it has long been known that mammalian adipose tissue is comprised of a variety of fatty acids incorporated into many different triglyceride species, the relative importance of the factors that regulate the fatty acid composition of this tissue and determine the distribution of these acids among the various types of triglyceride remains to be elucidated.

Alterations in the composition of dietary lipid rapidly modify the fatty acid composition of plasma triglyceride (1) and hence, in time, change congruently the composition of the adipose stores. Thus plasma triglyceride clearly can exert a controlling influence on the fatty acid composition of adipose tissue and, therefore, under some circumstances, must contribute in an important way to the lipid that accrues in the tissue. The second mechanism that can lead to accretion of lipid in fat tissue is of course storage of fatty acids that have been synthesized in situ. Indeed, lipogenesis in adipose tissue under in vitro conditions is so impressive that fat synthesis is often assumed to be the major process leading to growth of adipose stores in vivo. It is known, however, that synthesis of fatty acids, whether studied in the intact animal (2), in the isolated fat pad (3), or in particle-free preparations of adipose homogenates (4), results predominantly in the formation of saturated acids, whereas in the fat tissues of most mammals unsaturated acids are the predominant components (5). Thus if in situ synthesis of

* Submitted for publication September 9, 1965; accepted October 28, 1965.

This work was supported by grant MT-872 from the Medical Research Council of Canada and by a grant from the Quebec Heart Foundation.

† The work was performed while the author was a Markle Scholar in Medical Science.

Address requests for reprints to Dr. C. H. Hollenberg, Montreal General Hospital, University Medical Clinic, Montreal 25, Quebec, Canada. fatty acids is a major mechanism leading to accretion of lipid in fat tissue, extensive desaturation or preferential mobilization of the synthesized components must occur. There is as yet little information as to the extent these processes, over a relatively long period, affect fatty acids that are synthesized and incorporated in adipose tissue, and it is thus difficult to assess the contribution of fatty acid synthesis in fat tissue to the accumulation and composition of fatty acids in this tissue.

To study over several weeks the metabolism of fatty acids synthesized exclusively in adipose tissue, the in vivo incubation technique of Stein and Stein (6) was used with radioactive glucose replacing fatty acid in the incubation medium. This technique was also used to explore the extent to which fatty acids synthesized in the tissue mixed with acids originating in stored fat or plasma lipid before glyceride synthesis.

The data obtained indicate that in rats maintained on a standard mixed diet, incorporation of plasma lipid rather than in situ synthesis of fatty acids is the principal mechanism leading to accumulation of lipid in epididymal fat. It was also found that acids synthesized in this tissue were not segregated from acids of other origins but that considerable mixing occurred between these acids and those derived from bulk or plasma lipid before diglyceride formation.

\section{Methods}

Male Wistar rats (175 to $190 \mathrm{~g}$ ) maintained on Purina chow were used throughout the study.

The in vivo incubation technique used in this study was a modification of that reported by Stein and Stein (6) and has been previously described (7). The exteriorized fat pads were dipped in $3 \mathrm{ml}$ of Krebs-Ringer phosphate buffer ( $\mathrm{pH} 7.40$ ) containing $5 \%$ human albumin pretreated to remove bound fatty acid (8) and varying concentrations of crystalline insulin ${ }^{1}$ and glucose. Uni-

1 Eli Lilly, Indianapolis, Ind. 
TABLE I

Fatty acid composition of triglyceride classes*

\begin{tabular}{|c|c|c|c|c|}
\hline \multirow{2}{*}{$\begin{array}{l}\text { Fatty } \\
\text { acids }\end{array}$} & \multicolumn{4}{|c|}{ Triglyceride classes } \\
\hline & $\mathbf{0}$ & 1 & 2 & $3+$ \\
\hline & \multicolumn{4}{|c|}{ mole \% } \\
\hline S & 100 & 65 & 43 & 21 \\
\hline $\mathrm{U}_{1}$ & 0 & 35 & 47 & 44 \\
\hline $\mathrm{U}_{2}$ & 0 & 0 & 9 & 32 \\
\hline $\mathrm{U}_{3}$ & 0 & 0 & 0 & 3 \\
\hline
\end{tabular}

* The data shown are from a single experiment; all other studies were identical. In this and succeeding Tables, $\mathrm{S}$, $U_{1}, U_{2}$, and $U_{3}$ represent, respectively, saturated, monounsaturated, diunsaturated, and triunsaturated acids, and the triglyceride classes are designated by the total number of double bonds in each. The $3+$ class includes all triglycerides containing 3 or more double bonds.

formly labeled glucose, ${ }^{2} 5 \mu \mathrm{c}$ per $\mathrm{ml}$ of medium, was added in all studies. The period of incubation ranged from 20 to 45 minutes after which the pads were either excised or replaced in the animal for later study. Inconsequential amounts of radioactivity were recovered in lipid extracts of medium and plasma after incubation, but radioactivity was detectable in plasma water at this time. Recirculation of label was studied by incubating both pads in identical media except for the absence of radioactive glucose from one; less than $5 \%$ of the radioactivity present in the labeled pad had accumulated in the contralateral tissue either 1 or 14 days after incubation.

In some experiments, after incubation, the fat pads were treated with collagenase for preparation of free cells by the method of Rodbell (9). In other studies accumulation of radioactivity in adipose tissue was achieved by iv administration of radioactive glucose $(20 \mu \mathrm{c})$ to lightly anesthetized rats; epididymal fat was removed at varying times after the injection.

In all experiments the fat pads or free cells were extracted in an isopropanol-heptane-water system (10) and samples of both the organic and aqueous phases taken for radioactive counting. Portions of the organic phase were also used for triglyceride determination (11) and for saponification in ethanolic $\mathrm{KOH}(10 \%)$. After acidification, the acids were extracted into petroleum ether and samples taken for radioactive counting and for titration with $0.02 \mathrm{~N} \mathrm{NaOH}$. The remainder of the lipid extract was used for analysis of fatty acid composition by gas liquid chromatography (GLC) (12) and for a variety of other chromatographic procedures.

The major lipid classes were separated by thin layer chromatography (TLC) with silica gel $\mathrm{H}$ and a solvent system of petroleum ether: diethyl ether:acetic acid, 40:10:1 ( $\mathrm{vol} / \mathrm{vol} / \mathrm{vol})$. The various areas were identified by brief exposure to iodine after which the iodine was sublimed and the silica gel scraped directly into counting vials. Recovery of radioactivity by this method exceeded $90 \%$.

\footnotetext{
2 Merck Sharp \& Dohme, Montreal, Quebec.
}

The distribution of radioactivity among the saturated, monounsaturated, and diunsaturated acids of the adipose tissue was determined by separation of the fatty acid methyl esters on TLC with silver nitrate-impregnated silica gel $\mathrm{H}$ (13) with a solvent system of petroleum ether: diethyl ether: acetic acid, $45: 5: 1$. The areas were identified by staining channels with bromothymol blue, and three well-delineated regions were consistently seen representing the saturated, monenoic, and dienoic acids of the tissue. The acids were eluted by repeated washes with diethyl ether; recovery of radioactivity consistently exceeded $90 \%$. Results are expressed as per cent distribution of radioactivity.

The efficiency of this separation procedure was established in a number of ways. Methyl ester standards chromatographed in this system migrated as follows referable to methyl myristate: methyl myristate 1.00 , methyl palmitate 1.01 , methyl stearate 1.01 , methyl oleate 0.65 , methyl palmitoleate 0.59 , methyl linoleate 0.34 . Radioactive palmitic and oleic acids added to adipose extracts and carried through the procedure were recovered almost quantitatively in the appropriate areas. Finally, GLC analysis of the 0,1 , and 2 double bond areas prepared from adipose tissue extracts revealed that the various classes had been obtained in entirely pure form.

A similar system was used for the separation of the various classes of adipose tissue triglyceride. In this instance the developing solvents were chloroform: ethanol: acetic acid, 200:2:1, and the fractions were identified by staining channels with dichlorofluorescein. Four triglyceride fractions were eluted with diethyl ether representing those containing $0,1,2$, and 3 or more double bonds. The purity of the first three classes was established by GLC analysis of the constituent fatty acids (Table I), but that of the last group, which contained a heterogeneous collection of triglyceride types, obviously could not be established by this means. However, in view of the efficiency with which the other groups were separated, the quantitative recovery of tripalmitin in the fully saturated area, and the experience reported in the literature (14), it was very unlikely that the highly unsaturated classes were significantly contaminated with more saturated triglycerides.

After elution of the various triglyceride fractions, samples were taken for GLC and radioactive counting; recovery of radioactivity exceeded $90 \%$. The remainder of the eluates were saponified, and the fatty acids obtained were taken for radioactive counting and titration.

The various classes of diglyceride were separated in a similar system; the small quantity of diglyceride recovered in adipose extracts and the presence in these extracts of both the 1,2- and 1,3-diglyceride forms necessitated the introduction of several additional steps. Since, after incubation, the bulk of the diglyceride radioactivity was found in the 1,2 isomer (vide infra), this fraction was initially separated from the other lipid fractions by preparative TLC and mixed with carrier 1,2-diglyceride similarly isolated from adipose extracts that had been briefly hydrolyzed with alcoholic KOH. The mixed diglyceride pool was then developed on silver nitrate 
TABLE II

Fatty acid composition of diglyceride classes*

\begin{tabular}{lrrrrr}
\hline & \multicolumn{5}{c}{ Diglyceride classes } \\
\cline { 2 - 6 } $\begin{array}{c}\text { Fatty } \\
\text { acids }\end{array}$ & 0 & 1 & 2 & 3 & 4 \\
\hline & & \multicolumn{5}{c}{ mole $\%$} \\
$\mathrm{~S}$ & 99 & $49 \pm 2$ & 33 & 3 & $10 \pm 3$ \\
$\mathrm{U}_{1}$ & 1 & $51 \pm 2$ & 37 & 48 & 2 \\
$\mathrm{U}_{2}$ & 0 & 0 & 29 & 49 & $88 \pm 2$ \\
\hline
\end{tabular}

* Results shown are the means of four experiments except in the 4 double bond class, which represents three studies. Standard errors greater than 1 are shown.

silica gel in a solvent system of chloroform: methanol, $24: 1$, and diglyceride classes varying from fully saturated to those containing 4 double bonds were identified by staining channels with dichlorofluorescein. Each class was then eluted by repeated chloroform-methanol washes $(1: 1)$ and further adipose lipid added as carrier. The methyl esters of the fatty acids contained in the various fractions were formed, isolated, eluted, and counted as previously indicated. Due to the multiple procedures involved, only $70 \%$ of the diglyceride fatty acid radioactivity initially isolated by preparative TLC was recovered in the final extracts.

The possibility that during chromatography and elution, intermolecular exchange of fatty acids had occurred was excluded by studies in which radioactive 1,2-dipalmitin was added to a mixture of 1,2-diglycerides derived from an adipose extract; the radioactivity was quantitatively recovered in the fully saturated diglyceride area.

GLC analysis of the diglyceride fractions revealed that the classes were reasonably well separated (Table II). Slight contamination of the 2 double bond class with 1 double bond diglyceride was consistently observed. During elution from preparative TLC, a minor degree of diglyceride hydrolysis occurred, and small quantities of free acid and monoglyceride were produced. These products migrated close to the 4 double bond diglyceride area and were, in all probability, the source of the saturated and monounsaturated acids present in this fraction.

No attempt was made in these studies to determine the contribution of glycerol ethers to the radioactivity in the diglyceride fractions. On the basis of the chromato-

TABLE III

Radioactivity in free cells after in vivo incubation*

\begin{tabular}{lccc}
\hline \hline & \multicolumn{3}{c}{ Experiment } \\
\cline { 2 - 4 } & A & B & C \\
\hline $\begin{array}{l}\text { \% Total lipid in free cells } \\
\text { \% Total lipid radioactivity in } \\
\text { free cells }\end{array}$ & 1.1 & 3.6 & 9.9 \\
\hline
\end{tabular}

* In three experiments fat pads were incubated for 20 minutes and exposed to collagenase for varying periods. After separate extraction of free cells and residual tissues, the radioactivity and triglyceride content of each fraction were determined. graphic behavior of plasmalogenic diglyceride on silicic acid (15), ethers in the present study would probably have migrated with or ahead of the 1,3-diglyceride, and thus little contamination of the 1,2-diglyceride fraction would have occurred. However, this point was not critically established.

The radioactive counting procedures have been previously described (7). Both Packard Tri-Carb and Nuclear-Chicago liquid scintillation counters were used with dioxane as the solvent.

\section{Results}

Radioactivity in superficial and deeper adipose cells after in vivo incubation. As the incubation
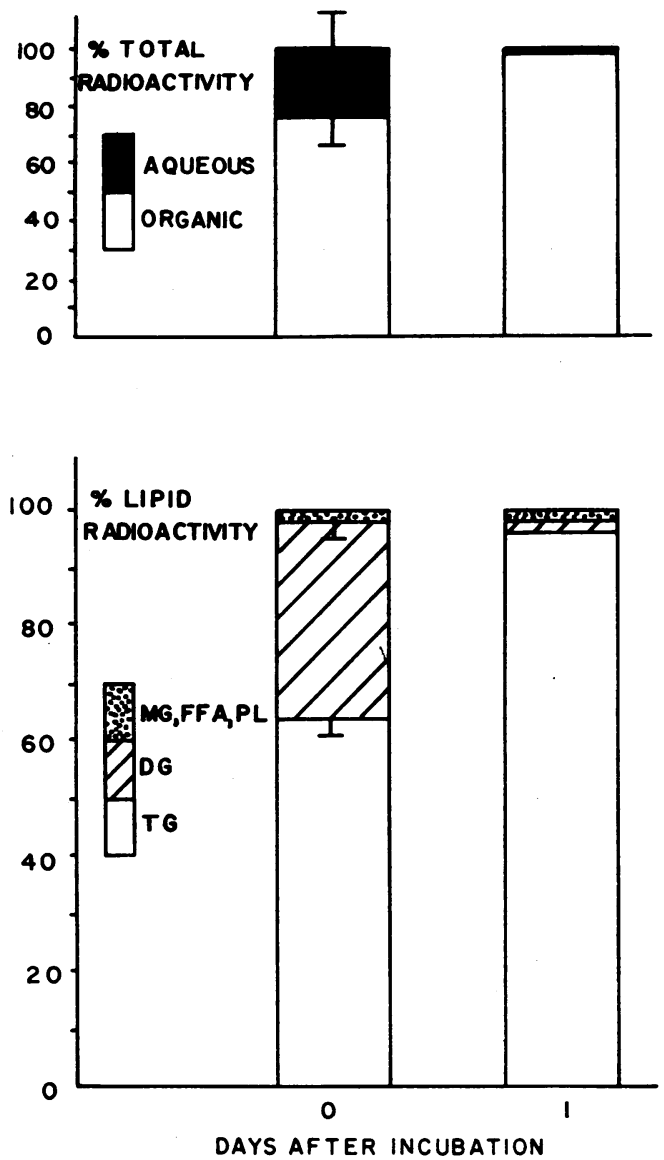

Fig. 1. Distribution of tissue and lipid RadioacTIVITY IMMEDIATELY AND 1 DAY AFTER INCUBATION. Six animals were used in this study, and all incubations lasted 45 minutes. In one experiment the medium glucose concentration was $100 \mathrm{mg}$ per $100 \mathrm{ml}$; in all others, $500 \mathrm{mg}$ per $100 \mathrm{ml}$. The other constituents of the medium were as previously described. TG, DG, MG, FFA, and $\mathrm{PL}$ represent triglyceride, diglyceride, monoglyceride, free fatty acid, and phospholipid, respectively. Brackets indicate standard errors. 
TABLE IV

Lipid synthesis from medium glucose

\begin{tabular}{|c|c|c|c|c|c|c|c|}
\hline \multirow{2}{*}{$\begin{array}{l}\text { Experi- } \\
\text { ment* }\end{array}$} & \multicolumn{3}{|c|}{ Incubation conditions } & \multirow[b]{2}{*}{ Lipogenesis $\dagger$} & \multicolumn{3}{|c|}{$\%$ Total fatty acid radioactivity } \\
\hline & Glucose & Insulin & Duration & & $\mathrm{s}$ & $\mathrm{U}_{1}$ & $\overrightarrow{\mathrm{U}_{2}}$ \\
\hline A (4) & $\begin{array}{c}m g / 100 ~ m l \\
500\end{array}$ & $\begin{array}{l}m U / m l \\
10\end{array}$ & $\begin{array}{l}\min \\
45\end{array}$ & $14 \pm 2$ & $\begin{array}{r}79 \ddagger \\
(63-89)\end{array}$ & $\begin{array}{c}18 \\
(8-31)\end{array}$ & 3 \\
\hline $\begin{array}{l}\mathrm{B}(2) \\
\mathrm{C}(2) \\
\mathrm{D}(2)\end{array}$ & $\begin{array}{l}100 \\
100 \\
100\end{array}$ & $\begin{array}{r}10 \\
0 \\
10\end{array}$ & $\begin{array}{l}45 \\
45 \\
20\end{array}$ & $\begin{array}{l}5 \\
4 \\
1\end{array}$ & $\begin{array}{l}80 \\
78 \\
80\end{array}$ & $\begin{array}{l}17 \\
20 \\
16\end{array}$ & $\begin{array}{l}3 \\
2 \\
4\end{array}$ \\
\hline
\end{tabular}

* Number of animals is shown in parentheses. In experiment $A$, the distribution of fatty acid radioactivity was determined in three of the four animals.

$\dagger$ Lipogenesis is expressed as microatoms of glucose carbon recovered in lipid per gram of tissue triglyceride. Standard error is shown.

$\ddagger$ Mean anil range.

system used in this study introduced radioactive glucose into adipose tissue by nonvascular channels, a disproportionate amount of radioactivity could have been taken up by a superficial population of cells that was not necessarily representative of the entire tissue. This problem was explored by incubating fat pads in the medium containing labeled glucose and by treating the tissues briefly with collagenase after excision. In this fashion a small proportion of the cells was released, which presumably was the most superficial. The data, shown in Table III, indicate that the proportion of total tissue radioactivity present in the free cells was the same as the fraction of the total tissue lipid present in these elements. Hence, it is likely that the radioactive glucose was widely distributed throughout the tissue during the incubation period.

Distribution of radioactivity among lipid classes. Figure 1 demonstrates the distribution of radioactivity between the aqueous and organic phases of the extract and among the various lipid classes immediately and 1 day after incubation. Immediately after incubation approximately $20 \%$ of the tissue radioactivity was in the aqueous phase; this fraction, presumably containing extracellular glucose, water-soluble glucose metabolites, and tissue glycogen, turned over completely within 24 hours. Immediately after incubation, $65 \%$ of the lipid radioactivity was present as triglyceride, and most of the remaining activity was recovered in the diglyceride fraction. In this system radioactive diglyceride was found to have a $t_{\frac{1}{2}}$ of about $80 \mathrm{~min}$ utes, and thus in samples removed 1 day after incubation, almost all of the tissue radioactivity was present as triglyceride. Conversion of diglyceride to triglyceride was the most probable fate of the diglyceride formed, although hydrolysis of at least a portion of the diglyceride cannot be excluded.

Immediately after incubation, over $90 \%$ of the diglyceride activity was in the 1,2 form, and the specific activity of diglyceride fatty acids was much higher than that of triglyceride acids at this time.

Distribution of radioactivity between glycerol and fatty acid was variable among experiments. In five studies of the type shown in Figure 1, $57 \%$ of lipid radioactivity was recovered in the fatty acid fraction immediately after incubation (range, 43 to $70 \%$ ); 1 day later this value was unchanged at $59 \%$ (range, 46 to $74 \%$ ). The variability noted among experiments was much less evident when the two pads of the same rat were compared; the standard error of the difference between the per cent label in fatty acid of the paired pads was $3 \%$.

Distribution of radioactivity among fatty acid classes. Total lipogenesis from medium glucose and distribution of radioactivity among the various classes of fatty acid are shown in Table IV. In these studies the composition of the medium and duration of incubation were varied, and the tissues were excised immediately after incubation. As expected, reduction in medium glucose concentration and in duration of incubation reduced the conversion of glucose to lipid; omission of insulin from the medium had only a slight effect, presumably due to the continuing circulation of insulin through the tissue.

The composition of the fatty acids synthesized was similar under all conditions of incubation; 
saturated acids comprised nearly $80 \%$ of all acids formed. This proportion is very close to reported values for rat (3) and human adipose tissue (16) studied in vitro and for mouse carcass lipid after iv administration of labeled acetate (2).

Although decarboxylation studies were not performed, it is very likely that the radioactivity had been introduced into the acids predominantly by total synthesis of fatty acids rather than by 2-carbon elongation. This view is supported by several observations in the literature; these include the exclusive recovery of label in acids of chain length 18 carbons or less after incubation of rat fat pads with acetate- $1-{ }^{14} \mathrm{C}(3)$ and the even distribution of ${ }^{14} \mathrm{C}$ among the carbons of carcass palmitic acid after glucose-U- ${ }^{14} \mathrm{C}$ administration to mice (17).

Additional experiments were performed in which the distribution of fatty acid radioactivity in rat epididymal fat was determined at varying times after iv injection of labeled glucose. As early as 15 minutes after administration of the isotope a
TABLE V

Distribution of fatty acid radioactivity after iv administration of glucose $-U-{ }^{14} C$

\begin{tabular}{ccccc}
\hline & & \multicolumn{3}{c}{$\%$ Total fatty acid radioactivity } \\
\cline { 4 - 5 } $\begin{array}{c}\text { Experi- } \\
\text { ment* }\end{array}$ & Timet & $\mathrm{S}$ & $\mathrm{U}_{1}$ & $\mathrm{U}_{2}$ \\
\hline & $\min$ & & & \\
$\mathrm{A}$ & 15 & 72 & 22 & 6 \\
$\mathrm{~B}$ & 60 & 87 & 10 & 3 \\
$\mathrm{C}$ & 80 & 81 & 14 & 5
\end{tabular}

* Each experiment represents one animal.

$\dagger$ Period from administration of isotope to excision of fat pad.

small amount of radioactivity was present in plasma triglyceride fatty acids; hence it cannot be definitely concluded that all the radioactive fatty acids recovered in adipose tissue after this time were synthesized in situ. Within these limitations the data obtained from these studies, shown in Table V, support the view that the compositions of acids synthesized during the in vivo incubation procedure and from circulating glucose were similar.

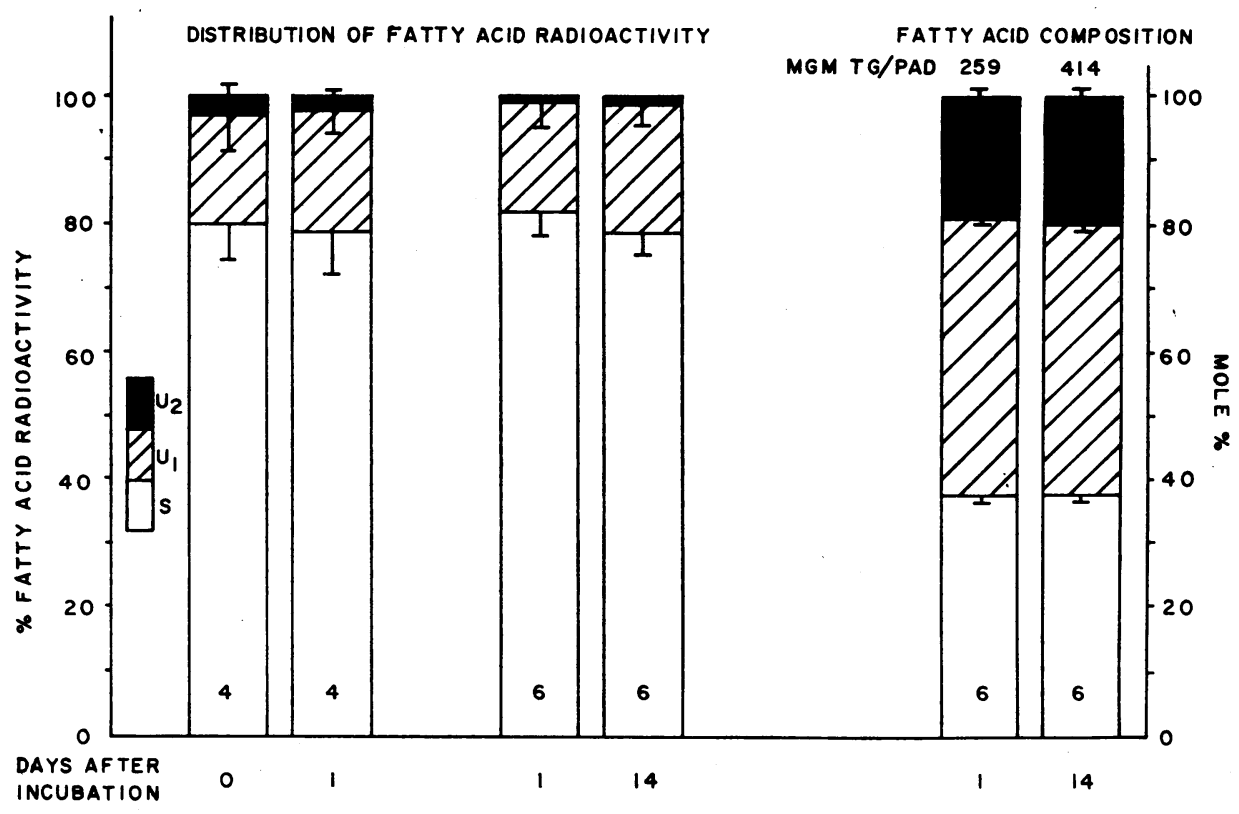

Fig. 2. RAdioActivity AND COMPOSITION OF ADIPOSE TISSUE FATTY ACIDS AT VARYING TIMES AFTER INCUBATION. In three of the four experiments shown on the left, the medium glucose concentration was $500 \mathrm{mg}$ per $100 \mathrm{ml}$; in one it was $100 \mathrm{mg}$ per $100 \mathrm{ml}$. All incubations lasted 45 minutes. In all of the 14-day experiments the pads were incubated for 20 minutes in a medium containing $100 \mathrm{mg}$ per $100 \mathrm{ml}$ glucose. The other ingredients of the media were as previously described. The standard errors are shown in brackets, the number of animals in each group at the foot of the columns. $S, U_{1}$, and $U_{2}$ represent, respectively, saturated, monounsaturated, and diunsaturated acids. 
TABLE VI

Effect of fasting on distribution of fatty acid radioactivity*

\begin{tabular}{cccc}
\hline \hline \multirow{2}{*}{$\begin{array}{c}\text { Dura- } \\
\text { tion of } \\
\text { fast }\end{array}$} & \multicolumn{3}{c}{$\%$ Total fatty acid radioactivity } \\
\cline { 2 - 4 } & $\mathrm{S}$ & $\mathrm{U}_{1}$ & $\mathrm{U}_{2}$ \\
\hline days & & & \\
0 & $78 \pm 5$ & $21 \pm 5$ & 1 \\
2 & $79 \pm 5$ & $20 \pm 5$ & 1 \\
\hline
\end{tabular}

* Four animals were studied. After incubation both pads were replaced for 24 hours; one was then removed and the animal fasted for $\mathbf{4 8}$ hours after which the second pad was excised. Mean values \pm standard error are shown.

Distribution of radioactivity among fatty acid classes 1 and 14 days after incubation. Two series of experiments were performed in this study; in the first, the fat pads were excised immediately and 1 day after incubation, whereas in the second both pads were replaced in the animal after incubation and removed 1 and 14 days later. In the latter group, in addition to determining the distribution of radioactivity among the various fatty acid classes, analyses were also made of the total fatty acid composition and of the triglyceride content of each pad. These data are shown in Figure 2.

In the first group of experiments over a 24hour period, no change in the distribution of fatty acid radioactivity was evident; saturated acids contained $80 \%$ of the fatty acid radioactivity immediately and $79 \% 1$ day after incubation. Although this proportion varied among experiments, it was very constant when the two pads were compared; the standard error of the difference between the per cent label in saturated acids of the paired pads was $2 \%$.

In the second group of studies, a very small but consistent reduction in the proportion of radioactivity recovered in saturated acids was evident; over the 2-week interval this fraction fell from 82 to $79 \%$. During this period the fat content of the fat pad increased an average of $60 \%$ while the fatty acid composition of the tissue remained constant with $40 \%$ of the total as saturated acids, $40 \%$ as monounsaturated acids, and $20 \%$ as diunsaturated acids. The fatty acid composition of rat plasma triglyceride was very similar although there were small differences between individual fatty acids in the plasma and adipose triglyceride fractions.
The minor change in label distribution over the 2 -week interval was probably the result of desaturation of saturated acids rather than preferential mobilization of these acids; as shown in Table VI, 48 hours of fasting produced no change in the distribution of fatty acid radioactivity despite a $50 \%$ fall in total lipid and tissue radioactivity. The equal rates of mobilization of saturated and monounsaturated acids and the minor degree of desaturation of saturated acids found in this study are compatible with previous reports in which long chain acids were directly incorporated into fat tissue $(7,18)$.

In the absence of extensive desaturation of saturated acids or of preferential mobilization of this class, it is difficult to assign to the in situ synthetic process a major role in the accretion of lipid that occurred over the experimental period. If a significant fraction of the lipid that accumulated in the tissue had been derived from synthesis, the total fatty acid composition of the tissue would have become progressively more saturated unless mechanisms were operative that markedly discriminated against the assimilation of saturated acid derived from plasma triglyceride. If it is assumed that in situ synthesis followed by storage accounted for as little as $50 \%$ of the lipid that accrued in the tissue, the proportions of saturated and monounsaturated acids in the tissue would not have remained constant unless the tissue had abstracted from plasma triglyceride monounsaturated and saturated acids in a ratio of $4: 1$. Since these two groups of acids were found to exist in equal proportions in rat plasma triglyceride (40\% each) and since the major acids in each group, palmitic and oleic, are equally well esterified by adipose tissue $(12,18)$, it is very difficult to envisage an assimilation process that would op-

TABLE VII

Distribution of fatty acids among triglyceride classes

\begin{tabular}{lcccc}
\hline \hline & \multicolumn{4}{c}{ Triglyceride classes } \\
\cline { 2 - 5 } & 0 & 1 & 2 & $3+$ \\
\hline $\begin{array}{l}\% \text { of total fatty acids (12)* } \\
\text { \% of fatty acid radio- } \\
\text { activity (11) }\end{array}$ & $3 \dagger$ & 17 & 29 & $51 \pm 2$ \\
\hline
\end{tabular}

* Number of animals is shown in parentheses.

† Mean values are shown. Standard error is indicated where greater than 1 . 
erate in such a fashion. A much more realistic interpretation of the data is provided by the assumption that plasma triglyceride, a fraction whose fatty acid composition resembled that of adipose tissue, was the origin not only of all the essential dienoic acids but also of the bulk of the saturated and monounsaturated acids that accumulated. It is thus probable that in rats of this age, plasma lipid rather than plasma glucose is the major precursor of adipose tissue lipid.

Distribution of fatty acid radioactivity among glyceride classes. Although there are some data that suggest the presence of a variety of discrete free acid pools in adipose tissue $(19,20)$, there is no information as to the extent synthesized acids mix with those derived from tissue stores or bulk lipid, either before or during the course of triglyceride synthesis in this tissue. To provide an initial approach to this problem, a study was made of the distribution of radioactive fatty acids among a variety of triglyceride and diglyceride classes differing in degree of unsaturation.

In the first series of experiments the fat pads were excised 24 hours after incubation, and the tissue triglyceride was separated into four classes containing $0,1,2$, and 3 or more double bonds. The 1-day interval between incubation and excision permitted conversion of all tissue radioactivity to triglyceride; previous studies have indicated no significant intermolecular rearrangement of triglyceride fatty acids over this interval (7). In these experiments, a mean of $83 \%$ of the fatty acid radioactivity was present in the saturated acid fraction, the remainder in monounsaturated acids. Table VII illustrates the distribution of total fatty acids and of fatty acid radioactivity among the four triglyceride classes studied.

Fatty acid radioactivity was recovered in each of the triglyceride species; the greatest proportion was in those triglycerides having 2 or more double bonds. Since only saturated and monounsaturated acids were synthesized, the proportion of fatty acid radioactivity in the 0 and 1 double bond triglyceride classes was expected to exceed the proportion of total fatty acids present in these species.

If the newly synthesized acids had been completely segregated and a fatty acid mixture comprised of $80 \%$ saturated and $20 \%$ monounsaturated acids presented to the esterifying system, the bulk of the fatty acid radioactivity would have been
TABLE VIII

Distribution of saturated acid radioactivity among triglyceride classes*

\begin{tabular}{lcccc}
\hline \hline & \multicolumn{4}{c}{ Triglyceride classes } \\
\cline { 2 - 6 } & 0 & 1 & 2 & $3+$ \\
\hline $\begin{array}{c}\% \text { Saturated acid } \\
\text { radioactivity }\end{array}$ & 10 & 25 & 21 & 44 \\
\hline
\end{tabular}

* In this experiment $80 \%$ of the total fatty acid radioactivity was in saturated acids.

recovered in the more saturated triglyceride classes. The finding of the reverse phenomenon offers strong evidence that the newly synthesized acids had mixed with acids derived from other sources at one or more stages of triglyceride formation. More direct data that mixing of this type had occurred was provided by the results of four experiments in which saturated acids comprised over $90 \%$ of the acids synthesized. In these studies $29 \%$ of the total fatty acid radioactivity was recovered in the group of triglycerides containing 3 or more double bonds; it is obvious that most of this radioactivity must have been in saturated acids. In a single experiment, shown in Table VIII, the distribution of the saturated acid radioactivity within each triglyceride class was determined directly; in this study $44 \%$ of the label in saturated acids was present in the most unsaturated class of triglycerides. It is evident that in these triglycerides saturated acids must have been associated in the same triglyceride molecules with dienoic acids derived from sources other than in situ synthesis. Thus the recovery of radioactive saturated acids in this fraction offers conclusive evidence that fatty acids of diverse origin had mixed during the course of triglyceride synthesis.

The next series of experiments was designed to determine the stage of triglyceride synthesis at which mixing had occurred. In addition to the possibility that the newly synthesized acids had been delivered into a pool of free acids of heterogenous origin, the newly formed acids could well have been esterified to pre-existing diglycerides, or alternatively, diglycerides composed of newly synthesized components could have been linked to fatty acids not formed in the tissue. To determine if any mixing occurred before the diglyceride stage of the esterification process, fat pads were excised immediately after incubation and the various 
TABLE IX

Distribution of saturated acid radioactivity among diglyceride classes

\begin{tabular}{cccccc}
\hline \hline & \multicolumn{5}{c}{ Diglyceride classes } \\
\cline { 2 - 6 } $\begin{array}{c}\text { Experi- } \\
\text { ment* }\end{array}$ & $\mathbf{0}$ & $\mathbf{1}$ & $\mathbf{2}$ & $\mathbf{3}$ & $\mathbf{4}$ \\
\hline & & \multicolumn{5}{c}{$\%$} \\
$\mathrm{~A}$ & 42 & 39 & 17 & 1 & 1 \\
$\mathrm{~B}$ & 36 & 39 & 22 & 1 & 2 \\
$\mathrm{C}$ & 42 & 35 & 21 & 1 & 1 \\
\hline
\end{tabular}

* Each experiment represents one animal.

classes of 1,2-diglyceride separated. These data are shown in Table IX.

Saturated acid radioactivity was recovered in diglycerides containing 0,1 , and 2 double bonds; the latter contained nearly $20 \%$ of the saturated acid radioactivity in the diglyceride fraction. It is evident that inclusion of radioactive saturated acid in the diunsaturated diglyceride class could have occurred only if newly formed saturated acids and dienoic acids of other origin had mixed before diglyceride formation. Although it is reasonable to assume that this mixing occurred at the free fatty acid stage of the esterification process, the data obviously do not exclude mixing by esterification of fatty acids to monoglyceride or to lysophosphatidic acid. There is no evidence, however, that these reactions are of importance or even operative in adipose tissue.

Proportion of total and radioactive saturated acid in trisaturated triglyceride. In those experiments in which the fat pads were removed 24 hours after incubation, the proportion of total and radioactive saturated acid recovered in fully saturated triglyceride was determined. In making these calculations no distinction was made between the various types of saturated acid. Since palmitic acid comprised $80 \%$ of the total saturated acids of the tissue and since this acid has been shown to form $80 \%$ of the saturated acids syn-

TABLE $\mathrm{X}$

Proportion of saturated acids in fully saturated triglyceride

\begin{tabular}{lc}
\hline $\begin{array}{l}\% \text { Total saturated acids } \\
\text { in trisaturated triglyceride }\end{array}$ & $8 \pm 1^{*}$ \\
$\begin{array}{l}\% \text { Saturated acid radioactivity } \\
\text { in trisaturated triglyceride }\end{array}$ & $16 \pm 1$ \\
\hline
\end{tabular}

* Mean values \pm standard error of 12 experiments are shown. thesized in fat tissue ( 3 ), this treatment was considered justified. These data are shown in Table $\mathrm{X}$.

The fraction of total saturated acid radioactivity recovered in trisaturated triglyceride consistently exceeded the proportion of total saturated acids present in this triglyceride class. This disproportionate formation of fully saturated triglyceride suggests that the newly synthesized acids had contributed to a precursor fatty acid pool whose final composition was more saturated than that which had given rise to the triglyceride already present in the tissue. This phenomenon, together with the other experimental findings, can be most readily explained by assuming that the small quantity of acid synthesized in these studies $(0.1 \mu$ mole per $g$ of tissue) had mixed with only a small fraction of the total free acid present in the tissue ( 2 to 4 $\mu$ moles per $\mathrm{g}$ ). In this way a small precursor fatty acid pool would have been formed, which, although highly saturated, would have contained acids of diverse origins.

TABLE XI

Distribution of saturated acids 1 and 14 days after incubation*

\begin{tabular}{lcc}
\hline & Day 1 & Day 14 \\
\hline$\%$ Total saturated acids & $8 \pm 1$ & $8 \pm 1$ \\
in trisaturated triglyceride & & \\
$\begin{array}{l}\% \text { Saturated acid radio- } \\
\text { activity in trisaturated } \\
\text { triglyceride }\end{array}$ & $17 \pm 2$ & $16 \pm 1$ \\
\hline
\end{tabular}

* Mean values \pm standard error of four experiments are shown.

Redistribution of saturated acids among triglyceride species. Previous data have demonstrated a slow redistribution of fatty acids among triglyceride classes in fat tissue (7). Since this information was obtained from studies in which long chain acids were directly incorporated into the tissue, it was considered desirable to determine whether the same phenomenon could be demonstrated with acids synthesized within the tissue.

This problem was approached by determining the proportion of saturated acid radioactivity present in fully saturated triglyceride 1 and 14 days after incubation of the tissue in radioactive glucose. The data, shown in Table XI, confirm the previous observations; over the 2-week interval the distribution of labeled saturated acids had not 
even approached equilibrium with the total saturated acids of the tissue.

In six studies in which observations were made 1 and 14 days after incubation, the proportion of total lipid radioactivity recovered in fatty acids was unaltered $(58 \pm 5$ vs. $60 \pm 6 \%) .^{3}$ In these experiments total lipid radioactivity decreased by a mean of $22 \%$ over the 13 -day interval.

These data, although entirely consonant with the very limited recycling of fatty acids that occurred between triglyceride species in this study, are not in keeping with estimates of re-esterification of fatty acids based on in vitro studies with fat tissue. The in vitro data have indicated that over $80 \%$ of the free fatty acids produced by triglyceride hydrolysis are re-esterified in the tissue with the glycerol of course being lost into the medium (21). Re-esterification to a similar extent in the present study would have resulted in a substantial increase in the fraction of total lipid radioactivity present in the fatty acid fraction. Hence it is possible that re-esterification is less prominent a phenomenon in vivo than in vitro perhaps because the intact circulation permits a much more efficient extraction of tissue free acids. This postulate is supported by data from studies with perfused adipose tissue; in these experiments free acid release was greater when the tissue was perfused than when it was incubated, and the fraction of free acid esterified was progressively decreased by increasing concentrations of albumin in the perfusate (22).

\section{Discussion}

The slow rate of fatty acid interconversion noted in the present study, although congruent with previous observations on the fate of palmitic acid directly incorporated into fat tissue $(7,18)$, appears to be somewhat at variance with the recent demonstration of extensive desaturation of stearic acid by adipose tissue $(3,23)$. These discrepancies may possibly reflect differences in rates of desaturation of stearic and palmitic acids, the latter being the major product of synthesis in fat tissue. Moreover, in the reported studies with stearic acid, the substrate was presented to the tissue as the free acid, the only form known to be reactive with

\footnotetext{
${ }^{3}$ Mean values \pm standard error are shown. The standard error of the difference between the per cent label in fatty acids of the paired pads was $2 \%$.
}

the desaturating system (24). In the present study, the initial observations were made after the synthesized acids had been incorporated into glyceride structures. Extensive further desaturation of these acids would have required, as an initial step, hydrolysis of a large fraction of the glyceride acids, and changes in the composition of the synthesized acids would only have been demonstrated had extensive re-esterification of the modified free acid products occurred. These processes would have produced considerable reshuffling of adipose triglyceride fatty acids, a phenomenon that did not occur. Hence the constancy of the composition of the synthesized acids over the 2 -week period is in keeping with the stability of the tissue triglycerides over this interval.

The conclusion that plasma triglyceride fatty acid rather than plasma glucose was the major precursor of the lipid deposited in rat epididymal fat in these experiments complements the result of other recent studies which have indicated that only a minute fraction of administered glucose can be recovered in the fatty acid fraction of rat white adipose tissue (25-27). Although all of these observations emphasize the role of plasma lipid in the accretion of fat in adipose tissue, they do not necessarily imply that adipose tissue is unimportant as a site of fatty acid synthesis, a conclusion that would be contrary to extensive data obtained chiefly from in vitro experiments. It has been suggested, but not proven, that acids synthesized within the tissue turn over rapidly in an active cytoplasmic compartment of the cell and thus may be discharged into the blood without entering the fat droplet (25). Support for this hypothesis is provided by recent data indicating that after intraperitoneal injection of labeled glucose, the specific activity of plasma glycerol greatly exceeds that of the glyceride-glycerol of white or brown adipose tissue (27). These results may well reflect rapid turnover of a very high specific activity pool of newly synthesized triglyceride.

If plasma triglyceride fatty acid is to be considered a major precursor of adipose tissue lipid, it is necessary to explain the constancy of the fatty acid composition of human adipose tissue in the face of radical alterations in the composition of dietary and hence plasma lipids (1). This phenomenon is undoubtedly a reflection of the slow turnover rate of adipose bulk lipid when the organism 
is in the isocaloric state. It has been known for years that in the growing rat and particularly in the fasted-refed animal that dietary alterations are rapidly followed by appropriate changes in adipose tissue composition (28).

Another well-known observation that must be reconciled with the results of the present study is the preponderant accumulation of monoenoic acids in the fat depots of animals fed a fat-free diet. In rats maintained on this regime, adipose tissue fatty acids are comprised of $60 \%$ monounsaturated and only $40 \%$ saturated acids (29). This phenomenon may be attributable in large part to the marked enhancement of monoene synthesis that is produced by fat-free feeding. In mice maintained on this regime, over $40 \%$ of the fatty acids formed from labeled acetate is of the monounsaturated variety (30). An even more unsaturated spectrum of acids can be incorporated into liver and hence plasma triglyceride if acids synthesized in fat tissue and rapidly released into the blood are desaturated in the liver before being esterified. In addition it is conceivable that the original pattern of synthesized acids can be modified further during assimilation of plasma triglyceride by fat tissue. As a hydrolytic step is involved in this process, free acids derived from plasma triglyceride may possibly be available to the desaturating system of adipose tissue before esterification and entry into the fat droplet.

The demonstration that fatty acids newly synthesized in the tissue and those derived from bulk lipid or plasma triglyceride can be incorporated into the same di- and triglyceride molecules raises the question as to the site in the adipose cell at which mixing of free acids of heterogenous origin occurs. Since esterification of fatty acids occurs with the particulate fraction of the adipose cell (31) and since both mitochondrial and microsomal preparations of this tissue bind free acids with a high degree of affinity (32), it is very likely that the subcellular particles are the sites involved. From the data presented, it is not possible to determine whether under normal circumstances the tissue triglycerides are derived from a single free acid pool or from multiple pools of differing compositions. Although in the present study the specific activity of saturated acids in trisaturated triglyceride exceeded that in other triglyceride classes, it is not known whether the same relation- ship would obtain under physiological conditions. If the quantity of acid synthesized from plasma glucose were minute compared to the quantity formed in these studies and compared to the size of the pool with which these acids mix, the labeled saturated acids could distribute in a more proportionate fashion than has been observed.

\section{Summary}

To study the contribution of fatty acid synthesis to the content and composition of fatty acids in rat adipose tissue, fatty acids were synthesized in rat epididymal fat by in vivo incubation in a medium containing uniformly labeled glucose. Immediately after incubation $80 \%$ of the fatty acid radioactivity was in saturated acids; this proportion was virtually unchanged 13 days later. Over this interval, the lipid content of the pads increased $60 \%$, and the total fatty acid composition remained unaltered at $40 \%$ saturated, $40 \%$ monounsaturated, and $20 \%$ diunsaturated acids. Due to the preponderance of saturated acids in the synthesized components, the absence of extensive desaturation or preferential mobilization of these acids, and the maintenance of the predominantly unsaturated character of the tissue over the experimental interval, it is evident that the process of in situ synthesis followed by direct incorporation of the synthesized acids had not provided the major portion of the lipid that accrued in the tissue. It is thus concluded that in rats maintained on a mixed diet, plasma triglyceride rather than plasma glucose may be the predominant precursor of adipose tissue fatty acids.

The distribution of the newly synthesized acids among a variety of triglycerides and diglycerides was also explored. Radioactive saturated acids were recovered in triglycerides containing 3 or more double bonds and in diglycerides containing 2 double bonds; hence acids synthesized in the tissue and dienoic acids derived from bulk lipid or plasma triglyceride had mixed, probably as free acids, before diglyceride formation. Apparently fatty acids formed in adipose cells are not segregated from acids of other origin.

Over a 13-day period there was no transfer of newly formed saturated acids between trisaturated triglycerides and other triglyceride species. In addition, since the proportion of lipid radioactivity present in the fatty acid fraction remained con- 
stant during this period, re-esterification of fatty acids derived from triglyceride hydrolysis was evidently not extensive. These observations indicate that after synthesis and storage of triglycerides in adipose tissue, little reorganization of the various triglyceride molecules occurs.

\section{Acknowledgments}

I am indebted to Dr. A. Angel for helpful advice. Rosemary Mackay and Maria Faluhelyi provided valuable technical assistance.

\section{References}

1. Hirsch, J., J. W. Farquhar, E. H. Ahrens, M. L. Peterson, and W. Stoffel. Studies of adipose tissue in man. A microtechnic for sampling and analysis. Amer. J. clin. Nutr. 1960, 8, 499.

2. Handwerck, V., and P. Favarger. Recherches sur la synthèse des graisses à partir d'acétate ou de glucose. VII. La formation indépendante des acides gras saturés et non saturés étudiée chez la souris in vivo. Helv. chim. Acta 1959, 42, 505.

3. Benjamin, W., and A. Gellhorn. The effect of diabetes and insulin on the biosynthesis of individual fatty acids in adipose tissue. J. biol. Chem. 1964, 239, 64.

4. Martin, D. B., M. G. Horning, and P. R. Vagelos. Fatty acid synthesis in adipose tissue. I. Purification and properties of a long chain fatty acidsynthesizing system. J. biol. Chem. 1961, 236, 663.

5. Mattson, F. H., and E. S. Lutton. The specific distribution of fatty acids in the glycerides of animal and vegetable fats. J. biol. Chem. 1958, 233, 868.

6. Stein, Y., and O. Stein. Metabolic activity of rat epididymal fat pad labeled selectively by an in vivo incubation technique. Biochim. biophys. Acta (Amst.) 1961, 54, 555.

7. Hollenberg, C. H. Transfer of fatty acids between triglyceride species in rat adipose tissue. J. Lipid Res. 1965, 6, 84.

8. Hollenberg, C. H. Effect of nutrition on activity and release of lipase from rat adipose tissue. Amer. J. Physiol. 1959, 197, 667.

9. Rodbell, M. Metabolism of isolated fat cells. I. Effects of hormones on glucose metabolism and lipolysis. J. biol. Chem. 1964, 239, 375.

10. Dole, V. P. A relation between non-esterified fatty acids in plasma and the metabolism of glucose. J. clin. Invest. 1956, 35, 150.

11. Van Handel, E., and D. B. Zilversmit. Micromethod for the direct determination of serum triglycerides. J. Lab. clin. Med. 1957, 50, 152.

12. Hollenberg, C. H., and A. Angel. Relation of fatty acid structure to release and esterification of free fatty acids. Amer. J. Physiol. 1963, 205, 909.
13. Barrett, C. B., M. S. J. Dallas, and F. B. Padley. The quantitative analysis of triglyceride mixtures by thin layer chromatography on silica impregnated with silver nitrate. J. Amer. Oil Chemists' Soc. 1963, 40, 580.

14. Blank, M. L., B. Verdino, and O. S. Privett. Determination of triglyceride structure via silver nitrate TLC. J. Amer. Oil Chemists' Soc. 1965, 42, 87.

15. Kiyasu, J. Y., and E. P. Kennedy. The enzymatic synthesis of plasmalogens. J. biol. Chem. 1960, 235, 2590.

16. Hirsch, J., and R. B. Goldrick. Serial studies on the metabolism of human adipose tissue. I. Lipogenesis and free fatty acid uptake and release in small aspirated samples of subcutaneous fat. J. clin. Invest. 1964, 43, 1776.

17. Handwerck, V., and P. Favarger. Recherches sur la synthèse des graisses à partir d'acétate ou de glucose. VIII. Les mécanismes d'élongation des acides gras saturés supérieurs étudiés chez la souris in vivo. Helv. chim. Acta 1959, 42, 508.

18. Stein, Y., and O. Stein. The incorporation and disappearance of fatty acids in the rat epididymal fat pad studied by the in vivo incubation technique. Biochim. biophys. Acta (Amst.) 1962, 60, 58.

19. Kerpel, S., E. Shafrir, and B. Shapiro. Mechanism of fatty acid assimilation in adipose tissue. Biochim. biophys. Acta (Amst.) 1961, 46, 495.

20. Vaughan, M. The metabolism of adipose tissue in vitro. J. Lipid Res. 1961, 2, 293.

21. Gorin, E., and E. Shafrir. Turnover of adipose tissue triglycerides measured by the rates of synthesis and release of triglyceride-glycerol. Biochim. biophys. Acta (Amst.) 1963, 70, 109.

22. Scow, R. O. Perfusion of isolated adipose tissue: FFA release and blood flow in rat parametrial fat body in Handbook of Physiology, section 5, Adipose Tissue, A. E. Renold and G. F. Cahill, Jr., Eds. Baltimore, Williams \& Wilkins, 1965, p. 437.

23. Gellhorn, A., and W. Benjamin. The intracellular localization of an enzymatic defect of lipid metabolism in diabetic rats. Biochim. biophys. Acta (Amst.) 1964, 84, 167.

24. Bloomfield, D. K., and K. Bloch. The formation of $\Delta^{8}$-unsaturated fatty acids. J. biol. Chem. 1960, 235, 337.

25. Patkin, J. K., and E. J. Masoro. Fatty acid synthesis in normal and cold-acclimated rats. Canad. J. Physiol. Pharmacol. 1964, 42, 101.

26. De Freitas, A. S. W., and F. Depocas. Fatty acid and glyceride-glycerol synthesis from glucose during high rates of glucose uptake in the rat. Canad. J. Biochem. 1965, 43, 437.

27. Hims-Hagen, J. Lipid metabolism in warm-acclimated and cold-acclimated rats exposed to cold. Canad. J. Physiol. Pharmacol. 1965, 43, 379.

28. Longenecker, H. E. Deposition and utilization of 
fatty acids of low molecular weight; and a fatty acid analysis of coconut oil. J. biol. Chem. 1939, 130, 167.

29. Longenecker, H. E. Deposition and utilization of fatty acids. I. Fat synthesis from high carbohydrate and high protein diets in fasted rats. J. biol. Chem. 1939, 128, 645.

30. Rous, S., and P. Favarger. Recherches sur la synthèse des acides gras. XIV. Influence de la composition des réserves sur la synthèse de différents acides gras chez la souris. Helv. physiol. Acta 1963, 21, 365.

31. Goldman, P., and P. R. Vagelos. The specificity of triglyceride synthesis from diglycerides in chicken adipose tissue. J. biol. Chem. 1961, 236, 2620.

32. Reshef, L., and B. Shapiro. Fatty acid adsorption by liver- and adipose-tissue particles. Biochim. biophys. Acta (Amst.) 1965, 98, 73.

\section{ANNOUNCEMENT OF MEETINGS}

The American Federation for Clinical Research will hold its Twentythird Annual Meeting in Atlantic City, N. J., in the Pennsylvania Room, Haddon Hall, on Sunday, May 1, 1966, at 9:00 a.m. Joint sectional meetings with The American Society for Clinical Investigation will be held on Sunday afternoon at Chalfonte-Haddon Hall, and additional meetings sponsored by The American Federation for Clinical Research will be held on Sunday evening.

The American Society for Clinical Investigation, Inc., will hold its Fifty-eighth Annual Meeting in Atlantic City, N. J., on Monday, May 2, at 9:00 a.m., in the Pennsylvania Room, Haddon Hall, and will join The American Federation for Clinical Research in simultaneous sectional meetings on Sunday afternoon, May 1, at Chalfonte-Haddon Hall.

The Association of American Physicians will hold its Seventy-ninth Annual Meeting in Atlantic City, N. J., in the Pennsylvania Room, Haddon Hall, on Tuesday, May 3, at 9:30 a.m., and in the Carolina Room, Chalfonte, on Wednesday, May 4, at 9:30 a.m. 